\title{
Understanding the Strategies Used to Translate Colloquial Egyptian Humour: A Study of Khaled Al Khamissi's Taxi (2006)
}

\author{
Sara A. Aldawood \\ Department of English \\ College of Languages \& Translation, King Saud University \\ Riyadh, Saudi Arabia
}

\begin{abstract}
Translators face immense challenges translating humor in a way that does not lose the essence of the original text. These difficulties are especially notable in translations between languages as disparate as Arabic and English, as they come from different language families. The present study aims to understand the strategies required for translating colloquial Egyptian humor into English and highlights the issues involved in the process of this translation. For this purpose, the study selected the book Taxi by Khaled Al Khamissi, as it is composed of 58 fictional monologues of taxi drivers in Cairo. The study highlights the challenges faced in translating colloquial Egyptian humor, along with the cultural differences that hinder its translation. The results show that translation is a major hurdle for culture-based and word-based humor because of cultural and linguistic differences; miscommunication and failure to translate humorous intent are due to lack of knowledge of the source culture. The impact of the humor is not transferred to the target text because a literal translation of word-based humour is not possible. A combination of procedures is used to transfer a humorous effect when translating culture-based humor. The study concludes that universal humour is easier to translate than culture-based humour, as the translator is familiar with the concepts involved.

Keywords: colloquial language, Egyptian humor, Khaled Al Khamissi's Taxi, translation strategies
\end{abstract}

Cites as: Aldawood, S. A. (2019). Understanding the Strategies Used to Translate Colloquial Egyptian Humour: A Study of Khaled Al Khamissi's Taxi (2006) Arab World English Journal for Translation \& Literary Studies, 3 (3) 188-197.

DOI: http://dx.doi.org/10.24093/awejtls/vol3no3.15 